\title{
Ser científico y hacer ciencia
}

\author{
To be a scientist and to do science
}

\begin{abstract}
Alberto Juan Dorta Contreras
Doctor en Ciencias de la Salud. Investigador y ProfesorTitular. Laboratorio Central de Líquido Cefalorraquídeo (LABCEL). La Habana, Cuba.
\end{abstract}

Quien crea pueblo, ha de habituar a los hombres a crear. ${ }^{1}$ José Martí

Hace más de 30 años, cuando era un estudiante universitario un artículo periodístico en una revista de divulgación popular me cambió la forma de ver la ciencia y el mundo científico.

Recuerdo que en este artículo se mencionaba una anécdota donde una maestra preguntaba a sus alumnos si alguno de sus padres era científico y uno de ellos dijo categóricamente: Mi padre es médico, es científico.

Y este artículo nos sacaba de un gran error que muchos aún cometemos, creemos y hasta lo divulgamos. Ser médico, al igual que otra profesión, no nos hace científicos.

El médico dejando a un lado todo lo hermoso e importante de su labor en los términos más objetivos, no es más que un técnico de nivel superior que simplemente repite los mismos procedimientos que le enseñaron y con la experiencia acumulada, primero de estudiar por los textos y luego a partir de sus propias vivencias va perfeccionando su tecnología aplicando el método científico.

Según la enciclopedia libre Wikipedia "el científico es, generalmente, una persona que se dedica a producir resultados en la ciencia moderna tanto como antigua haciendo uso del método científico." 2

Ahora bien, aplicar el método científico no lo convierte en científico al igual que el que aplica sus conocimientos de piano no se convierte en pianista.

El científico es algo más. Incluso conozco, como tal vez usted conozca también, a doctores en ciencia que no son científicos sino que hicieron ciencia apenas por un 
tiempo a veces muy corto para hacerse doctores en ciencia por algún motivo que no pretendo agotar: por el prestigio que entraña, por presión social, por metas de su colectivo o por circunstancias que lo hicieron estar en un lugar en el momento apropiado, y que luego de obtener el título con su correspondiente aumento salarial dejaron de hacer ciencia pero se autoproclaman y creen ser científicos.

Tiene el científico una alta responsabilidad con la ciencia que hace y con expandirla a todo su alrededor, con transmitirla día a día con extrema generosidad a todo el que lo rodea sin esperar recompensas por ello y hacer en todo momento posible ciencia.

No conoce el retiro a menos que existan condiciones físicas que lo limiten pero icuántos no siguen destellando ciencia desde su jubilación, con su ejemplo y obra, incluso hasta después de muertos! Ama y protege a la naturaleza y a su diversidad.

El hombre o la mujer científico se hace no se nace, depende mucho de los educadores que haya encontrado a su paso. Detrás de cada científico hubo un maestro, familiar o un conocido al menos que le inculcó ciencia y también de su autorrealización y el peso que tenga y observe dentro de la sociedad.

También pueden existir personas que sin tener una alta calificación me atrevería a catalogarlos de científicos. Por ejemplo en el movimiento de innovadores y racionalizadores que agrupa a la ANIR no son todos los que están pero si hay diamantes a veces en bruto que en esencia hacen ciencia.

Conozco obreros, técnicos y profesionales que hacen ciencia cada día y no saben que son esencialmente científicos. Pienso modestamente que ese es el futuro de hombres de ciencia del que hablaba y aspiraba Fidel en el año 1960 cuando dijo que el futuro de Cuba tenía que ser necesariamente un futuro de hombres de ciencia y pensamiento. ${ }^{3}$

No se es científico para cumplir un requisito sino que debe estar en la esencia de lo que hacemos.

En el científico debemos potenciar la modestia, el desinterés, la entrega, el espíritu de sacrificio, la laboriosidad, la constancia, la paciencia, el no sentirse jamás derrotado, la firmeza, la honradez en sus resultados, la ética, la constancia, el valor de reconocer el error, la crítica a los colegas y la autocrítica. Que no sabe nada y que cada día aprende algo nuevo. Esto se logra en los futuros científicos con el ejemplo de los verdaderos científicos.

Como educadores tenemos la responsabilidad de guiar a las nuevas generaciones en el camino de la ciencia para que aquellos o aquellas que quieran y sientan esa necesidad vital enrumben su vida.

Podemos como educadores dar algunos sanos consejos para los que pretenden hacerse científicos. Cada científico puede adicionar los que entienda a este modesto e incompleto comentario.

El trabajo del científico debe ser coherente. No es posible trabajar en muchos temas a la vez o dejar uno por otro de forma constante. Esto hace que se pierda mucho tiempo en divagar y no en profundizar.

La ciencia no es el trabajo de un día, ni de un semestre, no para una jornada o congreso. 
La ciencia es un proceso continuo y ascendente, con tropiezos y marcha atrás y con muchas incomprensiones.

El científico tiene que ser patriota, que sienta amor por la tierra que lo vio nacer y que lo formó. La ciencia no tiene fronteras pero los científicos si tienen patria.

El científico debe contar con herramientas adecuadas, hacer uso de las ciencias básicas y matrices de su ciencia. Estar bien informado, es estar a la altura de su tiempo para como decía Martí "Es criminal el divorcio entre la educación que se recibe en una época, y la época". ${ }^{4}$ Dominar en estos momentos las tecnologías de la información y leer mucho. No solamente de su "pedacito" de ciencia sino de todas las ciencias e incluso leer arte y literatura. El científico es necesariamente una persona culta sin llegar a ser un Leonardo Da Vinci de nuestros tiempos porque resulta imposible en una sola persona reunir todos los conocimientos actuales.

También tiene que conocer a otros científicos y mejor aún en persona. Este roce con otros científicos cubanos y de otras partes del mundo trasmite enseñanzas y virtudes compartidas con la humanidad toda. Debe conocer lo que hacen en el mundo como por ejemplo, los Premios Nóbel, al menos de la especialidad más cercana a la ciencia que hace. ¿Qué es eso de que conozcamos los Premios Oscar, los Grammy y no los Nóbel, aún cuando no compartamos los sesgos primer mundistas y por la brecha tecnológica que nos separan de ellos?

No pretendo en estas pocas letras agotar todo lo relativo al tema. Solamente invito a todos a que me ayuden con sus comentarios a completar una visión del científico que necesitamos y que tenemos el deber de formar.

Para el científico hacer ciencia es un deber y un derecho ineludible.

\section{REFERENCIAS BIBLIOGRÁFICAS}

1. Martí Pérez J. La Escuela de Artes y Oficios de Honduras. La América, Nueva York. Junio 1884. La Habana: Editora Nacional de Cuba;1965. [Obras Completas.1965;T8:15-8].

2. Científico. wikipedia sitio en Internet .[citado 1 Oct 2008] Disponible en: http://es.wikipedia.org/wiki/Cient\%C3\%ADfico

3. Castro Ruz F. Discurso del 15 de enero de 1960 ante la Sociedad Espeleológica de Cuba en el Paraninfo de la Academia de Ciencias de Cuba.

4. Martí Pérez J. Escuela de Electricidad. La América, Nueva York noviembre 1883. La Habana: Editora Nacional de Cuba;1965. [Obras Completas. 1965;T13:419-24].

Recibido: 21 de octubre de 2008.

Aprobado: 22 de octubre de 2008. 
Alberto Juan Dorta Contreras. Laboratorio Central de Líquido Cefalorraquídeo. Universidad de Ciencias Médicas "Dr. Miguel Enríquez". Apartado postal 10049. La Habana 11000. La Habana, Cuba. 